\title{
Low-grade fibromyxoid sarcoma of the hand: a case report
}

\author{
Guy Rubin • Micha Rinott • Alejandro Wolovelsky • \\ Irit Elmalach • Nimrod Rozen
}

Published online: 16 June 2010

(C) American Association for Hand Surgery 2010

\begin{abstract}
We report a case of low-grade fibromyxoid sarcoma with giant collagen rosettes in the hand of a 21year-old female. This is a clinically and radiological benign appearing tumor that has a high rate of recurrence and metastasis.
\end{abstract}

Keywords Hand · Low-grade fibromyxoid sarcoma . Chondrosarcoma

\section{Introduction}

Low-grade fibromyxoid sarcomas (LGFMS) are very rare soft tissue tumors. Evans first described the tumor in 1987 [1]. Most patients range in age from 25 to 46 years, but cases of this tumor in children have been reported [2-4]. The tumor typically occurs in the lower extremity, groin, head, and neck area [1,3-5], but rare cases of LGFMS have been found in the chest wall, shoulder, arm [6], forearm [7], abdominal (falciform ligament, ovarian, and small bowel mesentry) [8-10], and intracranial [11]. Two subtypes have

No benefits in any form have been received or will be received from a commercial party related directly or indirectly to the subject of this article.

G. Rubin $(\bowtie) \cdot$ M. Rinott $\cdot$ A. Wolovelsky $\cdot$ N. Rozen

Orthopaedic Department, Haemek Medical Center,

Afula, Israel

e-mail: guytalr@bezeqint.net

I. Elmalach

Pathology Department, Haemek Medical Center,

Afula, Israel

N. Rozen

Faculty of Medicine, Technion,

Haifa, Israel been recognized: classical low-grade fibromyxoid sarcoma and low-grade fibromyxoid sarcoma with giant collagen rosettes which was first reported in 1997 by Lane et al. and was termed hyalinizing spindle cell tumor with giant rosettes [12]. The immunohistochemical profile of the rosettes suggests a neural phenotype. The cells forming the rosettes are Leu-7, S100, and pgp 9.5 positive and the spindle cells are more consistent with fibroblast $[13,14]$. The immunohistochemical staining of the classic LGFMS is reported by some authors and is not consistent [15-17]. There is a characteristic balanced $\mathrm{t}(7 ; 16)(\mathrm{q} 34 ; \mathrm{p} 11)$ translocation [18]. The current treatment includes surgical excision $[3,4]$. There is a high rate of local recurrence [3] and lung metastasis [1].

In this article, we describe a case of LGFMS with giant collagen rosettes in the hand. We found in the literature only one case described in the hand among a series [12].

\section{Case Report}

A 21-year-old female noticed a mass located between the fourth and fifth metacarpal of her right hand for months. The mass was painless but was constantly enlarging. She was sent by her primary medical physician for an ultrasound examination that demonstrated a firm hypoecogenic mass sized $5.2 \times 2.7 \mathrm{~cm}$. The mass had a uniform texture with lobulated borders. On Doppler examination, there were few blood vessels. The differential diagnosis was giant cell tumor of tendon sheath and fibroma of tendon sheath. The patient was referred to our clinic for further evaluation. The patient was then sent for simple radiographs of the hand (Fig. 1) that demonstrated a mass that displaced the fifth metacarpal. Later, the patient was sent for a MRI study (Figs. 2, 3, and 4) that revealed an 


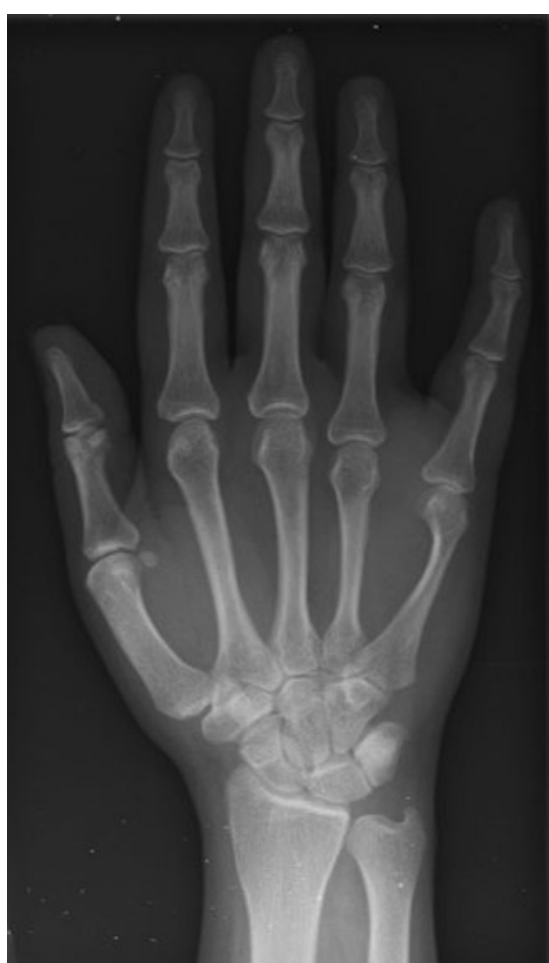

Figure 1 AP radiograph of the hand - the mass displaced the fifth metacarpal.

oval mass sized $5.2 \times 2.5 \times 2.4 \mathrm{~cm}$. The mass had smooth borders with heterogenic texture. The mass had displaced the ring and small finger flexor tendon sheaths and fourth and fifth metacarpals. The mass did not involve the bone nor penetrated the fascia. The mass was isointense in T1weighted images and hyperintense in T2-weighted images with heterogenic intensity with gadolinium. We performed

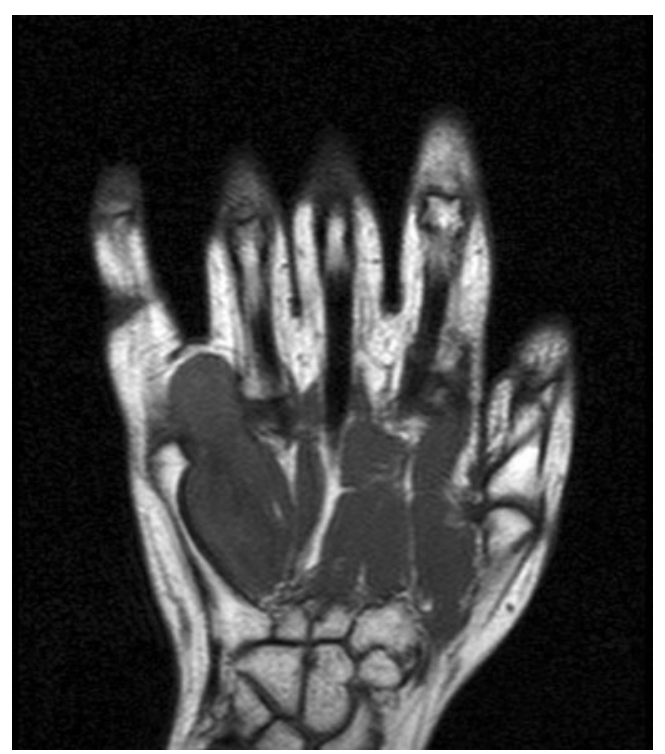

Figure 2 T1-weighted images - coronal view - the mass is isointense.

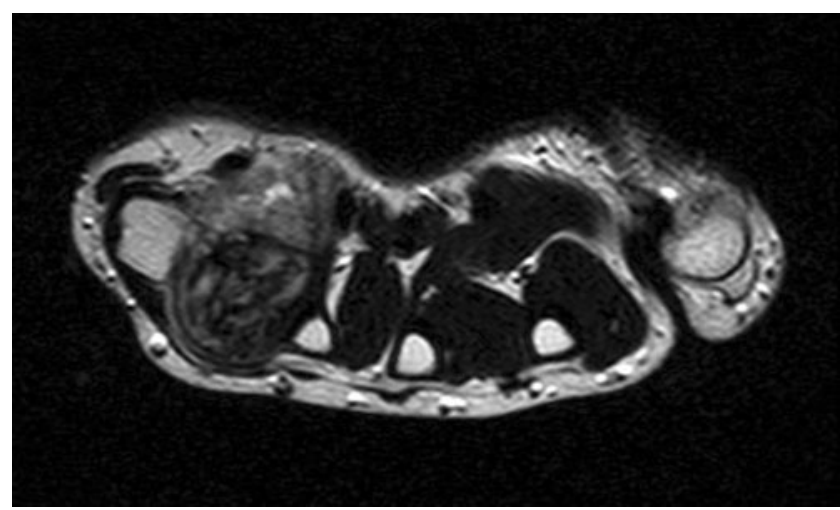

Figure 3 T2-weighted images - axial view - the mass is hyperintense.

an excisional biopsy in a dorsal approach. Histology examination showed a $5-\mathrm{cm}$ gray-white firm mass which microscopically appeared as a low-grade fibromyxoid sarcoma with giant rosettes. The tumor was unencapsulated with admixture of hypocellular collagenized and myxoid zones (Fig. 5) and areas with collagen rosettes showing a central core of hyalinized collagen surrounded by a cuff of epitheliod cells (Fig. 6). The hypocellular zones showed bland looking spindle cells with arcades of small blood vessels. The cells were negative on immunohistochemistry for Pankeratin, EMA, Desmin, S100, Smooth Muscle Actin, and CD34 and were positive only for Vimentin. The excision margins of the tumor necessitate a wider reexcision but the patient was unwilling for further operation. A computer axial tomography scan of the lungs revealed no lung metastasis. After 18 months of follow-up she has a good function of the hand with no evidence of recurrence in a MRI study.

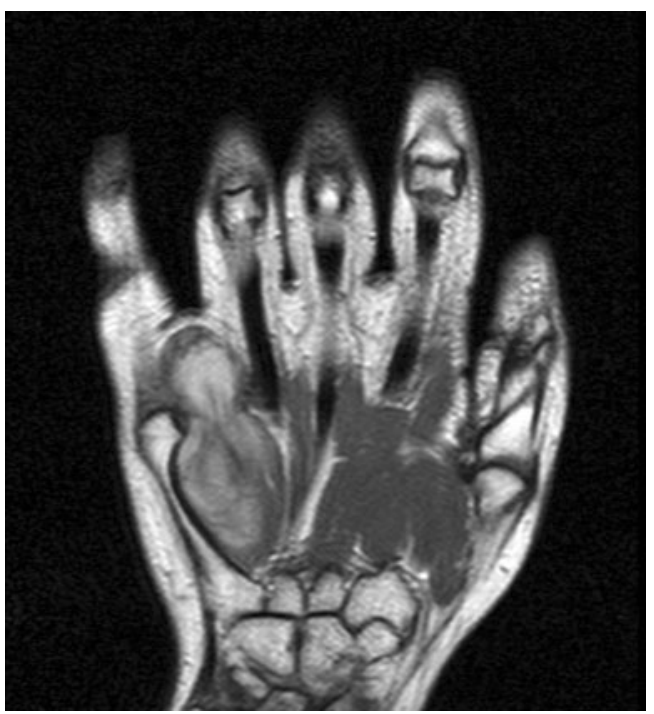

Figure 4 T1-weighted images with gadolinium-coronal view-the mass has heterogenic intensity. 


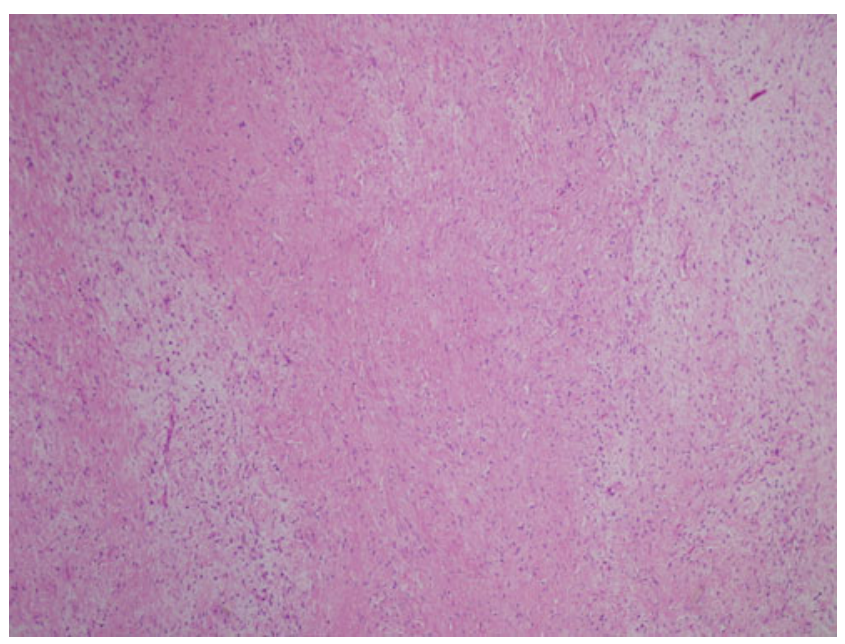

Figure 5 Low-grade fibromyxoid sarcoma consisting of very bland spindle cells in a collagen and myxoid background.

\section{Discussion}

Sarcomas of the hand are a rare occurrence and include chondrosarcoma, osteogenic sarcoma, and soft tissue sarcoma. Chondrosarcoma is the most common primary malignant bone tumor of the hand. Chondrosarcoma can be challenging in diagnosis as chondromas are far more common at this site and high index of suspicions should be taken. A chondrosarcoma should be suspected if a lesion is painful or if it recurs after routine curettage of an enchondroma. The recurrence and metastatic rates of chondrosarcoma of the hand are rare as compared to other sites of the body [19-21]. Thus, ray digital or whole bone amputation with the widest margins would be the safest mode of treatment [22].

Osteogenic sarcoma of the hand has been reported in only 36 proven cases [22]. In contrast to other sites of osteogenic sarcoma, hand tumors occur in older patients. Treatment includes wide en block excision, finger, or ray amputation with adjuvant chemotherapy [23]. The prognosis, as in chondrosarcoma, is better than in other sites of osteogenic sarcomas [24].

Soft tissue sarcomas are relatively rare in the hand and forearm. The most common histologic subtypes of soft tissue sarcoma seen in the hand are epithelioid sarcoma, synovial sarcoma, and malignant fibrous histiocytoma [25]. Approximately 6,000 new cases of soft tissue sarcoma are diagnosed each year in the United States, and only $15 \%$ of these are present in the upper extremity [26]. In the majority of patients, no predisposing risk factor can be identified [27]. The clinical presentation of the various types of soft tissue sarcomas in the upper extremity and hand may be similar. Mostly, patients note a painless mass that may have been present for a long time with recent growth $[25,28]$. Soft tissue sarcomas in the hand are frequently misdiagnosed as infection, ganglion, and lipoma. This may lead to inappropriate or a delay in treatment [27]. Campanacci et al. suggested that the prognosis is worse for patients who have a soft tissue sarcoma involving the hand than for those who have a similar lesion elsewhere in an extremity [29]. Staging should include computed tomography of the chest and axilla, the most common sites for soft tissue sarcoma metastasis [30]. The treatment of choice is wide excision with normal margins to avoid local recurrence. Amputation should be considered if negative margins cannot be achieved [25]. Neither chemotherapy nor irradiation improved the rate of survival of the patients who had a soft tissue sarcoma of the hand [25].

Low-grade fibromyxoid sarcomas are very rare soft tissue tumors with a benign appearance but with aggressive behavior. The current literature described only seven cases of metastatic pulmonary LGFMS [31] warranting long-term follow-up for all cases. The current management consists of wide local excision to avoid local recurrences $[3,4]$. There should be a high index of suspicion for this rare tumor and a low threshold for sending tissue for cytogenetic and/or molecular genetics [32]. Special precautions should be exercised in the interpretation of small biopsies of a spindle cell lesion with bland cytological features [33]. If the diagnosis is unclear there must be a detailed follow-up. The treatment of choice is a wide excision with normal margins to avoid local recurrence.

This rare tumor is first described here, in a young female's hand. The benign appearance of this mass both clinically and radiology made the evaluation process long and hence putting the patient in risk for complication. We suggest considering this tumor in the differential diagnosis when treating a benign looking tumor in the hand.

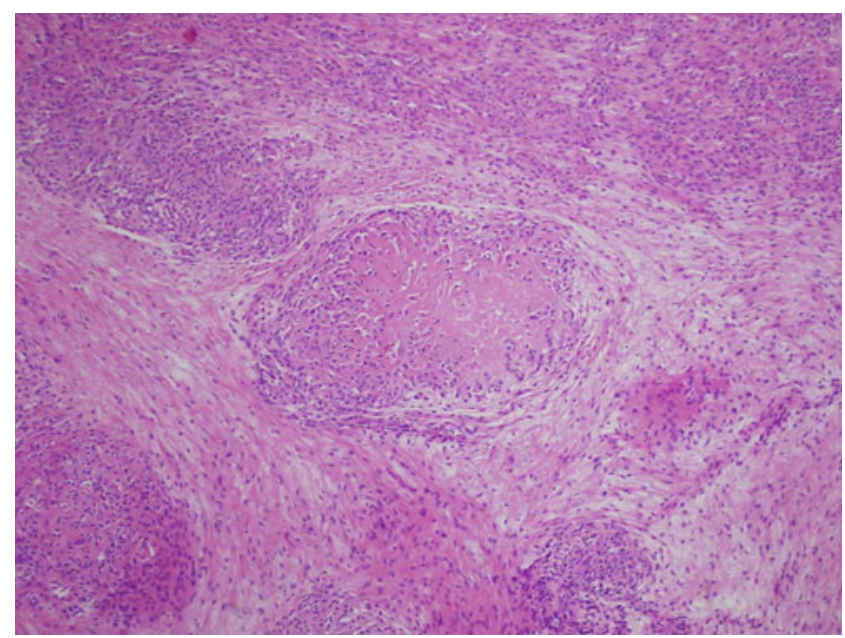

Figure 6 Low-grade fibromyxoid sarcoma with giant rosettes. 


\section{References}

1. Evans HL. Low-grade fibromyxoid sarcoma. A report of two metastasizing neoplasms having a deceptively benign appearance. Am J Clin Pathol. 1987;88:615-9.

2. Billings SD, Giblen G, Fanburg-Smith JC. Superficial low-grade fibromyxoid sarcoma (Evans tumor): a clinicopathologic analysis of 19 cases with a unique observation in the pediatric population. Am J Surg Pathol. 2005;29:204-10.

3. Evans HL. Low-grade fibromyxoid sarcoma. A report of 12 cases. Am J Surg Pathol. 1993;17:595-600.

4. Folpe AL, Lane KL, Paull G, Weiss SW. Low-grade fibromyxoid sarcoma and hyalinizing spindle cell tumor with giant rosettes: a clinicopathologic study of 73 cases supporting their identity and assessing the impact of high-grade areas. Am J Surg Pathol. 2000;24:1353-60.

5. Rando G, Buonuomo V, D'Urzo C, Vecchio F, Caldarelli M, Pintus C. Fibromyxoid sarcoma in a 4-year-old boy: case report and review of the literature. Pediatr Surg Int. 2005;21:311-2.

6. Nichols GE, Cooper PH. Low-grade fibromyxoid sarcoma: case report and immunohistochemical study. J Cutan Pathol. 1994;21:356-62.

7. Zamecnik M, Michal M. Low-grade fibromyxoid sarcoma: a report of eight cases with histologic, immunohistochemical, and ultrastructural study. Ann Diagn Pathol. 2000;4:207-17.

8. Fujii S, Kawawa Y, Horiguchi S, Kamata N, Kinoshita T, Ogawa T. Low-grade fibromyxoid sarcoma of the small bowel mesentery: computed tomography and magnetic resonance imaging findings. Radiat Med. 2008;26:244-7.

9. Harish K, Ashok AC, Alva NK. Low grade fibromyxoid sarcoma of the falciform ligament: a case report. BMC Surg. 2003;3:7.

10. Winfield HL, McKenney JK. Low-grade fibromyxoid sarcoma presenting clinically as a primary ovarian neoplasm: a case report. Int J Gynecol Pathol. 2007;26:173-6.

11. Saito R, Kumabe T, Watanabe M, Jokura H, Shibuya M, Nakazato $\mathrm{Y}$, et al. Low-grade fibromyxoid sarcoma of intracranial origin. J Neurosurg. 2008;108:798-802.

12. Lane KL, Shannon RJ, Weiss SW. Hyalinizing spindle cell tumor with giant rosettes: a distinctive tumor closely resembling low-grade fibromyxoid sarcoma. Am J Surg Pathol. 1997;21:1481-8.

13. Bejarano PA, Padhya TA, Smith R, Blough R, Devitt JJ, Gluckman JL. Hyalinizing spindle cell tumor with giant rosettes - a soft tissue tumor with mesenchymal and neuroendocrine features. An immunohistochemical, ultrastructural, and cytogenetic analysis. Arch Pathol Lab Med. 2000;124:1179-84.

14. Nielsen GP, Selig MK, O'Connell JX, Keel SB, Dickersin GR, Rosenberg AE. Hyalinizing spindle cell tumor with giant rosettes: a report of three cases with ultrastructural analysis. Am J Surg Pathol. 1999;23:1227-32.

15. Fukunaga M, Ushigome S, Fukunaga N. Low-grade fibromyxoid sarcoma. Virchows Arch. 1996;429:301-3.
16. Goodlad JR, Mentzel T, Fletcher CD. Low grade fibromyxoid sarcoma: clinicopathological analysis of eleven new cases in support of a distinct entity. Histopathology. 1995;26:229-37.

17. Ugai K, Kizaki T, Morimoto K, Sashikata T. A case of low-grade fibromyxoid sarcoma of the thigh. Pathol Int. 1994;44:793-9.

18. Reid R, de Silva MV, Paterson L, Ryan E, Fisher C. Low-grade fibromyxoid sarcoma and hyalinizing spindle cell tumor with giant rosettes share a common $\mathrm{t}(7 ; 16)(\mathrm{q} 34 ; \mathrm{p} 11)$ translocation. Am J Surg Pathol. 2003;27:1229-36.

19. Bovee JV, van der Heul RO, Taminiau AH, Hogendoorn PC. Chondrosarcoma of the phalanx: a locally aggressive lesion with minimal metastatic potential: a report of 35 cases and a review of the literature. Cancer. 1999;86:1724-32.

20. Dahlin DC, Salvador AH. Chondrosarcomas of bones of the hands and feet - a study of 30 cases. Cancer. 1974;34:755-60.

21. Patil S, de Silva MV, Crossan J, Reid R. Chondrosarcoma of small bones of the hand. J Hand Surg Br. 2003;28:602-8.

22. Calundruccio JH, Jobe MT. Tumors and tumorous conditions of hand. In: Canale ST, editor. Campbell's operative orthopaedics. 11th ed. Philadelphia: Mosby; 2007.

23. Link MP, Goorin AM, Horowitz M, Meyer WH, Belasco J, Baker A, Ayala A, Shuster J. Adjuvant chemotherapy of high-grade osteosarcoma of the extremity. Updated results of the Multi-Institutional Osteosarcoma Study. Clin Orthop Relat Res. 1991; 8-14

24. Carroll RE. Osteogenic sarcoma in the hand. J Bone Joint Surg Am. 1957;39-A:325-31.

25. Brien EW, Terek RM, Geer RJ, Caldwell G, Brennan MF, Healey JH. Treatment of soft-tissue sarcomas of the hand. J Bone Joint Surg Am. 1995;77:564-71.

26. Lewis JJ, Brennan MF. Soft tissue sarcomas. Curr Probl Surg. 1996;33:817-72.

27. Green DP. Green's operative hand surgery. Philadelphia, Pa: Elsevier/Churchill Livingstone; 2005.

28. Terek RM, Brien EW. Soft-tissue sarcomas of the hand and wrist. Hand Clin. 1995;11:287-305.

29. Campanacci M, Bertoni F, Laus M. Soft tissue sarcoma of the hand. Ital J Orthop Traumatol. 1981;7:313-27.

30. Gadd MA, Casper ES, Woodruff JM, McCormack PM, Brennan MF. Development and treatment of pulmonary metastases in adult patients with extremity soft tissue sarcoma. Ann Surg. 1993;218:705-12.

31. Kalebi AY, Hale MJ. Pulmonary metastasis from a deltoid subcutaneous low-grade fibromyxoid sarcoma with giant collagen rosettes. Hum Pathol. 2008;39:1553-4.

32. Wu X, Petrovic V, Torode IP, Chow CW. Low grade fibromyxoid sarcoma: problems in the diagnosis and management of a malignant tumour with bland histological appearance. Pathology. 2009;41:155-60.

33. Domanski HA, Mertens F, Panagopoulos I, Akerman M. Lowgrade fibromyxoid sarcoma is difficult to diagnose by fine needle aspiration cytology: a cytomorphological study of eight cases. Cytopathology. 2009;20:304-14. 